\title{
History of internal medicine at Baylor University Medical Center, part 2
}

\author{
W. Mark Armstrong, MD, Michael Emmett, MD, AND John S. Fordtran, MD
}

\section{THE EMMETT ERA}

Upon Dr. John Fordtran's retirement in 1995, a national search was organized to find the next chief of internal medicine at Baylor University Medical Center (BUMC). There were many strong applicants from the institution, the city, and the nation. Eventually, Dr. Michael Emmett was felt to be the best candidate to lead BUMC's internists (Figure 1). Dr. Emmett had been a practicing nephrologist at BUMC since 1976, and in 1986 he became chief of the division of nephrology, medical director of the Ruth Collins



Figure 1. Dr. Michael Emmett, chief of internal medicine at Baylor University Medical Center from 1996 to the present.
Diabetes Center, and the Ralph Tompsett Professor of Medicine at BUMC. He had served as president of the medical staff in 1994 and chairman of the medical board in 1995 and therefore had an understanding of how the hospital functioned and had developed a cordial working relationship with the administration.

Dr. Emmett was a popular choice among the various internal medicine groups. He is recognized as an outstanding clinician who has a strong interest in medical education. He has practiced in a clinical setting and therefore is aware of the problems confronting private practitioners. He was a popular choice with the housestaff as well, who have acknowledged his teaching abilities by bestowing several teaching awards upon him. Because he had been at BUMC for many years and was a good friend of Dr. Fordtran, the transition of chiefs went very smoothly.

Dr. Emmett's primary interest in being chief of medicine is continued improvement of the educational programs at BUMC. He has a hands-on approach, participating in morning report, serving as an attending physician for the medicine ward teams, attending the daily noon conferences, and giving many lectures throughout the year. He continues to conduct one of the daily conferences for the third-year medical students, and he gives many of the noon conference lectures himself. He does not limit his lectures to nephrology but is able to lecture on a wide variety of subjects. He is sought out by other local hospitals and by national organizations to present his lectures at conferences and continuing medical education seminars.

Dr. Emmett has also been very interested in bringing physicians to BUMC who are engaged in meaningful research. He is particularly proud of the recent additions of Drs. Richard Boland, Paul Grayburn, and Gary Davis. Dr. Emmett has worked to maintain harmony not only within the internal medicine department but also throughout the hospital.

His national reputation is reflected in his selection as a master in the American College of Physicians. He has served on the committee of the American Board of Internal Medicine that is responsible for writing the nephrology certifying examination (the board exam). As a further manifestation of his national reputation, he was chosen as a vice president for professional education of the National Kidney Foundation. This role allows him to interact with the most prominent clinical nephrologists in the nation, and the position adds further luster to BUMC and the medical residency program.

\section{Current issues}

As medicine has changed, many issues have arisen that do not fall cleanly within one department. For example, most gastrointestinal endoscopic procedures are performed in the gastroenterology laboratory, where direction and quality are maintained by the Division of Gastroenterology. Nongastroenterologists such as colon and rectal surgeons are permitted to do procedures in the lab but must meet credentialing guidelines. However, some endoscopies are also performed outside the gastroenterology lab (for example, in the operating rooms), where the gastroenterology division cannot monitor the qualifications of physicians performing the procedures. A second example is credentialing for fiber-optic bronchoscopies. In the pulmonary lab, pulmonary physicians perform all of the fiber-optic bronchoscopies, but other physicians have requested the use of the fiber-optic scope in the operating room or intensive care unit (ICU). The credentialing committee must sanction the physicians who can perform these procedures. Even after initial credentialing, difficulties arise in assessing ongoing performance and outcomes.

Several invasive cardiologists would like to do peripheral vascular procedures, both diagnostic and therapeutic. This has created a controversy throughout the hospital, particularly among radiologists and vascular surgeons. This controversy involves not

From the Department of Internal Medicine, Baylor University Medical Center, Dallas, Texas.

Corresponding author: W. Mark Armstrong, MD, Department of Internal Medicine, Baylor University Medical Center, 3500 Gaston Avenue, Dallas, Texas 75246. 

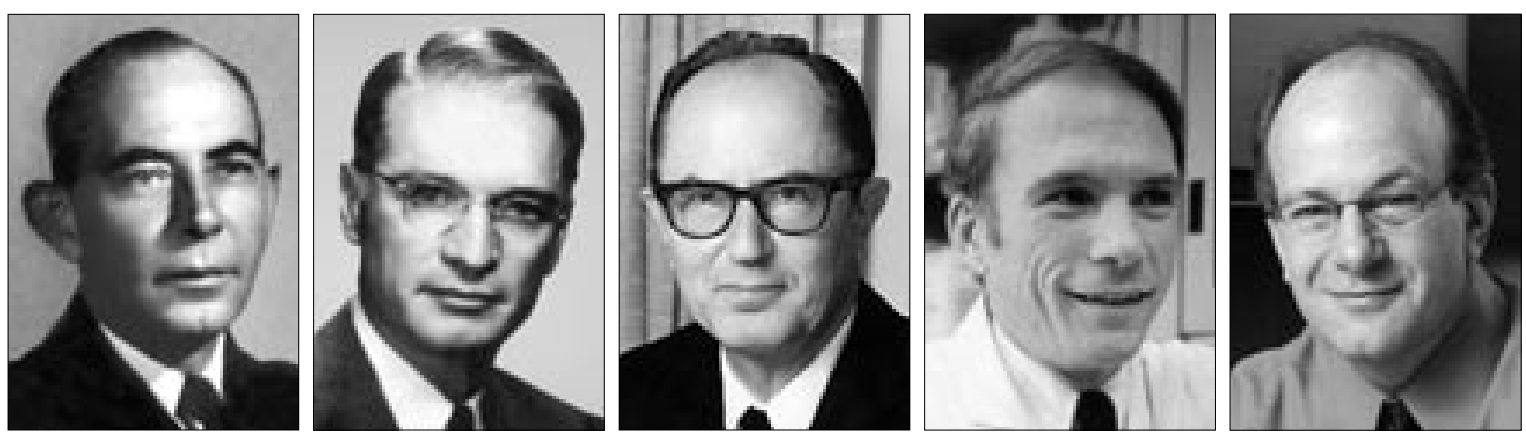

Figure 2. Chiefs of medicine at UT Southwestern. Left to right: Dr. Tinsley R. Harrison, Dr. Charles Burnett, Dr. Donald W. Seldin, Dr. Daniel W. Foster, and Dr. Gregory Fitz.

only Dr. Emmett but also chiefs of other divisions and departments. A task force headed by Dr. Sue Bornstein has been developed to resolve this interdepartmental issue.

These multidepartmental regulatory issues and the many requests for non-internal medicine specialists to do "internal medicine" procedures, as well as for internists to perform "surgical or radiologic" procedures, complicate the role of the chief of medicine to some extent. He must constantly review the impact of these decisions on the department and the hospital.

Within the Division of General Internal Medicine, the general internists are adamant that they are qualified to be the principal physician responsible for the care of their patients admitted to the ICU. Although there has been pressure to have intensivists care for ICU patients, the general internists maintain that as long as they are properly credentialed, they should be allowed to manage the care of these patients.

\section{Nursing issues}

One of the major changes within the hospital that has occurred during Dr. Emmett's tenure is the disappearance of the skilled nursing facility from the BUMC campus. This has had a major impact on how patients, especially the elderly, are cared for in the hospital. Formerly, the skilled nursing facility was used when patients no longer required care in an acute care setting. Patients could be transferred to this step-down unit but continue to receive comprehensive care from the primary physician and consultants. Care also included physical therapy, intravenous antibiotics, total parenteral nutrition, and comprehensive wound care. However, with the change in payment structure for skilled nursing facilities, it was no longer financially feasible for BUMC to maintain the inhouse unit. Now, if patients require skilled nursing, they must be transferred to a facility remote from the BUMC campus. It is expected that this will lead to longer hospital stays for Medicare patients who continue to require complex medical care but who otherwise could have been transferred to a skilled nursing facility if one were close at hand. The Department of Internal Medicine has requested that the administration find a site on the BUMC campus for a skilled nursing unit.

An important topic that involves the entire medical center is the use of nurse practitioners, physician assistants, and other allied health professionals within the hospital. The first allied health professionals to be employed at BUMC were the certified registered nurse anesthetists, who have worked in the operating room for many years and were hired by the hospital. Later, nurse practitioners were employed in the neonatal ICU, and their pres- ence was considered essential due to a shortage of physicians in that subspecialty. Subsequently, surgeons hired their own physician extenders to help them in the operating room and in postoperative care.

The Department of Internal Medicine has taken the stance that physician extenders should be used to perform tasks appropriate for their training but should not replace physicians in the primary role of patient care. Both Dr. Fordtran and Dr. Emmett have felt that physicians should continue to be responsible for performing the histories and physicals on patients admitted to the hospital. They should be the ones analyzing data and formulating the plan of care for the patient. The physician extenders can be used to collect data and help the physician in completing these tasks, but the allied health professional should not be responsible for these very important parts of patient care. The internists maintain that if patients are ill enough to be admitted to the hospital, then their care should be directed by physicians. This is especially true of patients admitted to the internal medicine floors and the ICUs and patients who are not admitted for a "routine" procedure. Nurse practitioners and physician assistants are utilized in the outpatient arenas (for instance, at the senior health clinics).

\section{UT SOUTHWESTERN-BAYLOR RELATIONSHIP AND THE \\ E. R. HAYES LECTURESHIP}

There have been 5 chiefs of internal medicine at the University of Texas Southwestern Medical Center (UT Southwestern) (Figure 2). Dr. Tinsley Harrison (1944-1950) was widely admired for his book, Failure of the Circulation, which was the bible of cardiac circulatory dynamics in the late 1930s and 1940s. While he was chief of medicine at UT Southwestern, he wrote and edited the first edition of Principles of Internal Medicine, which next to Osler's was probably the most important textbook of the 20th century. Eight of the 53 chapters in the first edition were written by doctors from Dallas, some of whom were practicing physicians at Baylor University Hospital. Dr. Harrison instituted a 6-week rotation at Baylor in which senior medical students took a preceptorship in the offices of Baylor internists. Students came to the office, made house calls, and made rounds. Dr. Paul Thomas was involved, and some of his students were Drs. Don Brown, Billy Oliver, and Clark Douglas.

Dr. Charles Burnett served as chief of medicine for 1 year (1951). In 1949, just prior to becoming chief of medicine at UT Southwestern, Burnett and coworkers emphasized a major complication of the Sippy regimen for treatment of peptic ulcer disease. 
They were the first to use the term "milk-alkali syndrome," which was later often called Burnett syndrome $(1,2)$.

Dr. Burnett was replaced by Dr. Donald W. Seldin (19521988). Dr. Seldin was originally known for his research in the physiology of the kidney, and he is an outstanding clinician and teacher in all areas of internal medicine. In 1952, at age 32, he was not only chief of medicine but also the only full-time member of the department. However, he received much help and strong support from several Baylor internists, including Drs. Al Harris, Sam Shelburne, Paul Thomas, Grady Reddick, and E. R. Hayes. Dr. Seldin's deep and lasting friendship with these men, and with other Baylor physicians, resulted in an excellent relationship between Baylor and the medical school. He helped recruit Dr. Tompsett as the first full-time chief of internal medicine at Baylor in 1957, and he initiated a formal rotation of junior medical students at Baylor, which was a huge boost to the development of Baylor teaching in internal medicine. Dr. Seldin was the principal speaker when Paul Thomas was honored at Baylor.

Dr. Daniel W. Foster (1988-2003) followed Dr. Seldin as chairman of medicine at UT Southwestern. He is a worldrenowned expert in diabetes, is an inspiring and gifted teacher, and is one of the most respected internal medicine chiefs in the USA. Dr. Foster was and is a highly popular speaker at BUMC grand rounds. His son Chris completed his internal medicine residency at BUMC and currently is a general internist at BUMC. Dr. Daniel Foster continued to send junior medical students to BUMC for their internal medicine rotation, which has remained a major element in BUMC's progression towards being a premier postgraduate medical education program in internal medicine. In 2002 he helped BUMC recruit Dr. Richard Boland as its new chief of gastroenterology.

In 2003 Dr. Foster retired and was replaced by Dr. Gregory Fitz. Dr. Fitz obtained his medical degree from Duke University and did his internal medicine residency training at the University of California at San Francisco. He remained in San Francisco for fellowship training in gastroenterology. Prior to accepting the position of chief of medicine at UT Southwestern, Dr. Fitz was chief of gastroenterology at the University of Colorado in Denver. His research interests include epithelial ion channels, cellular mechanisms of insulin resistance, and biliary secretion. Dr. Fitz is a member of the two premier organizations that influenced the early development of internal medicine, the Association of American Physicians and the American Society for Clinical Investigation. He is widely known as an outstanding mentor for young physician-scientists and for his clinical acumen.

Initially, the cordial relationship between Baylor internists and UT Southwestern was based on close friendships and on mutual assistance with the teaching of medical students and residents. Later, when Medicare reimbursement for the care of patients at Parkland Hospital demanded daily visits by fulltime members of UT Southwestern, the use of volunteer Baylor internists as attending physicians at Parkland Hospital became impractical. Close friendships maintained the relationship in the 1970s and 1980s, but these were likely to dim with the passage of time and with the appointment of new leaders at the two institutions. In the early 1990s, Dr. E. R. Hayes intervened.

Dr. E. R. Hayes (Figure 3) graduated from Baylor University College of Medicine in Dallas in 1938. He did internship and



Figure 3. Dr. E. R. Hayes. residency training in Lexington, practiced for a few years in Kentucky, and joined the US Army in 1940. From 1946 to 1950, he took fellowship training with Dr. Cecil Watson in Minnesota, and in 1948 he and Dr. Ancel Keyes published a paper in the Journal of Clinical Investigation on serum cholesterol levels in normal people. In 1950 he returned to Dallas and was employed half-time at UT Southwestern and half-time at the Veterans Affairs (VA) Hospital. Simultaneously he began the practice of internal medicine, with Baylor University Hospital as his hospital. Starting in 1952 he was a consultant for the US Army, and in this position he visited all army hospitals within the vast part of the country between the Mississippi River and the Rocky Mountains. He was primarily responsible for ensuring that all army hospitals in the central USA were of high quality.

During his 40 years of active practice at Baylor, Dr. Hayes had only one partner, Dr. Paul Neubach. When Dr. Hayes retired in 1990, Dr. Neubach proposed the establishment of a yearly E. R. Hayes lecture. Money to endow the lectureship was donated by Dr. Hayes' friends on the medical staff and from some of his patients. Initially it was envisioned that the lectureship would promote and emphasize general internal medicine. Dr. Hayes was involved in choosing the speaker, and his choice for the inaugural address was Dr. Donald Seldin. The second and third lectures were devoted to the role of general internal medicine, but after that Dr. Hayes decided on a different direction for the lectureship. He wanted all subsequent speakers to be members of the faculty of medicine at UT Southwestern. He did not explain his reason for this shift, but in time it became apparent that his purpose was to promote the relationship between BUMC and UT Southwestern. Dr. Foster gave the lecture in 1996. In conjunction with the lectures, Dr. Hayes and his wife, Mary, hosted an elegant dinner at the Park Cities Club for guests from BUMC and UT Southwestern. This annual dinner, whose guests span 65 years of medical history in Dallas, has become a much-anticipated, joyful, and magical occasion. It has markedly enhanced, and hopefully will help preserve, the outstanding relationship among physicians from the two institutions.

\section{RESEARCH}

Medical research is an integral component of all great medical centers. A vibrant research program advances medical knowledge and our understanding of normal human physiology. It also provides direct and indirect benefits to almost every facet of a medical institution. Research changes the way we think about disease processes and their treatments. Translational and clinical medical research brings novel and innovative diagnostic and therapeutic procedures to the bedside, directly improving the care of patients. Furthermore, the intellectual environment generated by an active medical research program promotes practical discussions relevant to patient care, encourages healthy skepticism about current options, and stimulates the entire medical staff to read, probe, and 
question current medical dogma. A successful research program transforms the entire atmosphere of an institution.

During the first 25 years of its existence, Baylor University College of Medicine struggled with a series of financial and academic crises. The school's leadership was principally preoccupied with efforts to reverse a negative evaluation in the Flexner Report (1910) and to gain class A accreditation from the American Medical Association. One could charitably describe the school's research efforts during that first quarter century as very modest. The status of research improved during the 1930s and 1940s, principally as a result of the work of Dr. Joseph Hill and Dr. E. E. Muirhead. Dr. Hill's laboratory made major discoveries and advances in blood storage techniques, blood typing, and transfusion therapy. He invented a practical method to vacuum desiccate blood plasma. Baylor University Hospital's blood bank became world renowned, and Baylor became the first hospital to implement routine Rh blood typing. Dr. Arvel Haley, an internist (whose four sons all became prominent Dallas physicians), coauthored several papers with Drs. Muirhead and Hill dealing with transfusion reactions and in 1947 published one of the earliest papers describing the use of peritoneal dialysis to treat acute kidney failure resulting from a transfusion reaction.

When Baylor University College of Medicine moved from Dallas to Houston in 1943, the few scientists on the campus also went to Houston or moved across town to the new medical school that was developing in Dallas. Consequently, the already small medical research program at Baylor University Hospital atrophied.

Dr. Henry Winans became the chief of internal medicine in 1947. He published a number of case reports and clinical reviews. However, he did not-nor did any of the other members of the department-carry out original medical research. Dr. Ralph Tompsett became the chief of medicine in 1957. Dr. Tompsett had been a successful medical researcher during his tenure at Cornell and the New York Hospital, where he published in vitro and animal studies elucidating mechanisms of bacterial infection. He also participated in a number of human studies dealing with the treatment of pneumococcal pneumonia, tuberculosis, meningitis, endocarditis, and some of the very earliest clinical studies of parenteral glucocorticoids. However, at BUMC, Dr. Tompsett chose to focus on the clinical services and the teaching program and did not continue medical research.

In 1979 Dr. John Fordtran, the chief of gastroenterology at UT Southwestern, was recruited to BUMC to succeed Dr. Tompsett as chief of internal medicine. Dr. Fordtran was, and is, an internationally renowned clinical investigator. He transplanted his research laboratory to BUMC, where it continued to thrive. A number of "experts" had predicted that a research program of the first rank could not thrive, or even survive, at BUMC because of the private-practice environment and the lack of a close medical school affiliation. Dr. Fordtran proved them wrong. The impressive quality of the research carried out in his laboratory is validated by the many publications in outstanding peer-reviewed medical journals and a phenomenal 40 -year record of continuous funding from the National Institutes of Health (NIH)! The research has focused on the discovery and exploration of fundamental physiologic concepts. The lab has also elucidated the pathophysiology of intestinal transport in patients with a variety of gastrointestinal and kidney disorders. The work resulted in many therapeutic and diagnostic innovations, including GoLYTELY (a colon-cleansing solution), PhosLo (calcium acetate, a phosphate binder for patients with kidney disease), and the only laxative that has been "invented" in several decades (Miralax). Several diseases such as microscopic colitis were first identified at BUMC. The laboratory continues to function, and recent studies have identified several gastrointestinal defects and transport abnormalities in patients with cystic fibrosis. Finally, the textbook Dr. Fordtran published in collaboration with Dr. Marvin Sleisenger is recognized as the definitive gastroenterology text throughout the world, and this adds to the academic environment of the Division of Gastroenterology and the Department of Internal Medicine.

Medical research and academic/scholarly pursuits may be divided into three broad categories:

1. Original research, conceived by the investigator to test a hypothesis

2. Case reports, review articles, clinical reviews

3. Large clinical trials sponsored by the government (e.g., NIH, Armed Forces) or by pharmaceutical/device companies

In general, category 1 research is considered most important because it has the potential to fundamentally change our understanding of human physiology, disease processes, and disease therapy. Category 2 research/academic pursuits are most significant when published in nationally/internationally respected peer-reviewed journals. Such work sometimes has an important impact on diagnostic or therapeutic concepts. Category 3 research helps bring new drugs and devices to the market, and participating physicians are able to offer new and otherwise unavailable drugs and devices to our patients. Such research encourages BUMC physicians to stay abreast of the latest treatment protocols and technology. Also, physicians who participate in large trials interact with colleagues from around the world, and this enhances their knowledge and BUMC's reputation. Lastly, large multicenter trials may also generate significant revenue. This form of research becomes most important to BUMC and the department of medicine when our hospital functions as one of the major study sites and/or the BUMC investigators are study leaders, are major participants in the writing of the manuscript, and are prominently recognized, together with BUMC, in the published output.

The quality of research, regardless of the category, is best demonstrated, measured, and quantitated by publication in peerreviewed journals.

The research output of the Fordtran lab has been, and continues to be, primarily of the category 1 type. In addition, multiple case reports and reviews of clinical topics (category 2 ) have been published. The quantity of publications and quality of the journals (more or less quantified by a journal's "impact factor") in which the work was published have been outstanding. For many years, the Fordtran lab was the only locus within BUMC's Department of Internal Medicine at which category 1 research took place. Drs. Michael Emmett, Lawrence Schiller, Kenneth Fine, and many others participated in this research as co-investigators and coauthored the manuscripts that emanated from this lab. One of Dr. Fordtran's trainees and colleagues, Dr. Güenter Krejs, is now the chief of medicine at the Karl-Franzens Medical School in Graz, Austria. Annually or biannually he sends one of his most 
promising gastroenterology trainees to BUMC to participate in research projects in the Fordtran laboratory and most recently in Dr. Boland's genetics lab (see below). These individuals include Drs. H. F. Hammer, H. H. Wenzl, B. W. Aichbichler, C. Gruy-Kapral, C. Hogenauer, and F. Fuerst. The work of the lab has been published in the Journal of Clinical Investigation, New England Journal of Medicine, Annals of Internal Medicine, Kidney International, Gastroenterology, American Journal of Human Genetics, and others. A large number of category 2 publications were also generated by these individuals.

Dr. Lawrence Schiller is an internationally renowned authority on the causes and treatment of constipation and diarrhea. He speaks frequently at national and international meetings and regularly publishes review articles and book chapters dealing with these problems. He also studies new treatments for patients with diarrhea, constipation, and irritable bowel syndrome.

In 2002, Dr. Gary Davis was recruited from the University of Florida to head BUMC's subdivision of hepatology. He is widely recognized as a leader in the field of hepatitis, has directed a number of large clinical trials of the treatment of both viral and nonviral liver disease, and organizes and speaks at national and international meetings. At BUMC he continues his work in this area. Dr. Davis also collaborates closely with the surgical liver transplant team, follows the transplanted patients before and after the procedure, and collaborates on a number of research projects.

Other members of the Division of Gastroenterology have contributed to the medical literature by carrying out and publishing research in categories 2 and 3. Drs. Daniel Polter, Kent Hamilton, and Daniel DeMarco worked on the pathophysiology and treatment of peptic ulcer disease, laser treatment of peptic ulcers, and placement of percutaneous gastrostomy tubes.

The solid organ transplant team initiated and led by Dr. Göran Klintmalm has made numerous discoveries and advances. Dr. Klintmalm was one of the original investigators pioneering the clinical use of the antirejection drug cyclosporine. BUMC was also one of the first centers to utilize ex vivo pig livers as a bridge to transplantation in desperately ill patients. Current efforts to establish the first pancreas islet cell transplant program in the Southwest are under way. In these efforts, the internal medicine department's divisions of nephrology, hematology, oncology, gastroenterology, and hepatology have made major research contributions. Dr. Thomas Gonwa, who led the transplantation nephrology section from 1987 to 2001, carried out category 1, 2, and 3 research, published numerous papers, and became one of the world's experts on the impact of liver transplantation on kidney function. His team participated in many multicenter studies of new immunosuppressive and antiinfective drugs and protocols.

Dr. Robert Collins of the hematology/oncology division published a series of articles describing and defining graft-versus-host disease after bone marrow or liver transplantation. He also coauthored a number of publications with Dr. Joseph Fay and Dr. Luis Piñeiro exploring the pathophysiology and treatment of several immunologic complications of bone marrow transplantation. Dr. Fay currently heads a clinical team collaborating with Dr. Jacques Banchereau of the Baylor Research Institute in studies of dendritic cell-based anticancer vaccines and devotes all of his professional time to these endeavors. They are currently employing this technology in patients with widely disseminated cancer, especially melanoma, and plan to extend this work to other malignancies. Many BUMC oncologists participate in multiple phase II and III trials of chemotherapeutic agents and protocols (category 3). Drs. Joanne Blum and Joyce O'Shaughnessy study novel agents to treat breast cancer and investigate preventive strategies for subjects with a high risk of breast cancer. This group also studies genetic aspects of breast cancer and has established a counseling service for patients and their families. Dr. Stephen Jones directs a number of multicenter studies of new chemotherapeutic agents, and Drs. Robert Mennel, Barry Cooper, and John Pippin collaborate in many of these studies. Dr. Marvin Stone is the director of BUMC's interdisciplinary cancer center, and the laboratories he directs carry out studies on control of the immune system, multiple myeloma, and amyloidosis. Dr. Stone and his colleagues also study innovative methods of cancer treatment. In addition, Dr. Stone is a nationally recognized medical historian, has published many medical history papers, and is the 2004 president of the American Osler Society.

Drs. John Nemunaitis and Charles "Casey" Cunningham are applying basic genetic manipulation techniques to viral vectors and tumor vaccines to treat patients with refractory malignancies. These scientists are truly bridging the gap between very basic bench research and the bedside, thereby providing hope to patients with very dismal prognoses.

Research in the cardiology division includes Dr. Cara East's studies of hyperlipidemia therapies and participation in multicenter antihypertension and lipid control trials. Dr. William Roberts, the world's preeminent cardiac pathologist, who was recruited to BUMC from the NIH, has been the editor of the American Journal of Cardiology for many years, and that journal is now based at BUMC. He also is the editor of BUMC Proceedings. Dr. Roberts publishes numerous reviews, case series, commentaries, and critiques of clinical cardiology. His research efforts are primarily centered on the analyses of gross and microscopic cardiac pathology in almost every disorder that affects the heart. $\mathrm{He}$ is also an expert on the development of atherosclerosis and prevention strategies. Drs. Azam Anwar and Jeffrey Schussler publish small series and case reports, and a number of our cardiologists participate in device studies.

In the nephrology division, Dr. Andrew Fenves participates in several NIH- and pharmaceutical-sponsored trials, including studies of analgesic nephropathy, maintenance of dialysis angioaccess, and prevention of intravenous postcontrast kidney failure. Dr. Yousri Barri investigates kidney function in transplant patients and preservation of kidney function. Drs. Michael Wiederkehr and Carlos Zayas published a number of papers prior to their arrival at BUMC and continue their academic pursuits. Dr. Michael Emmett, the current chief of internal medicine, continues to collaborate with Dr. Fordtran on studies of gastrointestinal/kidney physiology and pathophysiology and also publishes reviews and critiques in the areas of acid-base and electrolyte physiology and pathology and mineral metabolism.

Dr. Alan Menter of the dermatology division actively investigates the genetics and therapy of skin disorders, especially psoriasis. BUMC was one of the first clinical centers to utilize cyclosporine for the treatment of psoriasis, and Dr. Menter continues to participate in multiple phase II and III psoriasis therapy studies. Collaborating with Dr. Anne Bowcock (formerly at UT 


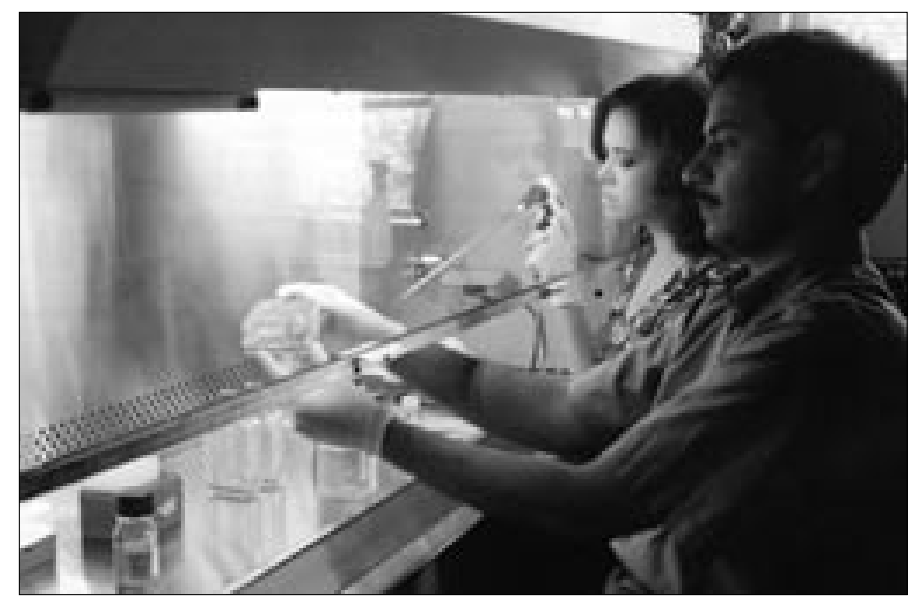

Figure 4. Ajay Goel, PhD (front) and Jennifer Rhees work with cultures of colon cancer cell lines in Dr. Boland's research lab. Photo: Jennifer Beck/Gittings.

Southwestern and now at Washington University, St. Louis), he has described several genetic links to psoriasis. These findings have been extensively reported in excellent peer-reviewed medical literature (Science) and in the lay press. Dr. David Whiting is a renowned hair loss expert who carries out and publishes categories 2 and 3 research. Drs. Jennifer Cather and William Abramovits regularly publish case reports and therapeutic protocols. Dr. Cather also studies new treatments for skin lymphomas and skin manifestations of graft-versus-host disease. Dr. James "Jimmy" B. Howell was a recognized authority on malignant melanoma and a high-profile crusader for public education and awareness to screen for this malignancy. He also published extensively on the "basal cell carcinoma syndrome." Dr. Coleman Jacobson publishes articles dealing with the history of dermatology and is the president of the International Dermatology Society.

Dr. Zaven Chakmakjian, BUMC's first chief of endocrinology, published a series of papers describing the measurement of sex hormones in normal subjects and patients with a variety of disorders. Dr. Samuel Marynick coauthored several papers on calcium disorders and parathyroid hormone. He also coauthored a major paper on endocrine aspects of cystic acne with Dr. Chakmakjian and others. Dr. Priscilla Hollander of the endocrinology division participates in a number of multicenter trials of new drugs and therapeutic innovations for control of diabetes and obesity. She serves on expert panels and on many study section groups.

Dr. Gary Tunell has been the chief of neurology since 1990 . $\mathrm{He}$ and his group actively participate in several multicenter trials of new treatments for multiple sclerosis, amyotrophic lateral sclerosis, seizures, and stroke rehabilitation. They speak regularly at national and international meetings.

The rheumatology division led by Dr. Andrew Chubick, infectious diseases division led by Dr. William Sutker, and pulmonary/ critical care division led by Dr. Robert Black also participate in multicenter trials of new pharmaceuticals, biologic agents, and medical devices. Dr. Mark Millard has participated in a number of controlled trials evaluating the use of glucocorticoids and antiinflammatory agents for the treatment of asthma.

Drs. Ziad Haydar and Wilson Weatherford have created a subdivision of geriatrics within the general internal medicine division and have generated several successful research efforts, some in collaboration with the gerontology section at Johns Hopkins.
BUMC actively recruited Dr. John Fordtran to become the chief of medicine because he had a stellar international reputation, broad clinical acumen, and excellent administrative leadership skills. The clinical research laboratory he brought to BUMC was perceived as an "added benefit" but was not a major factor in his recruitment. However, after Dr. Fordtran's arrival, it became apparent that his clinical studies and regular publication in outstanding journals were having

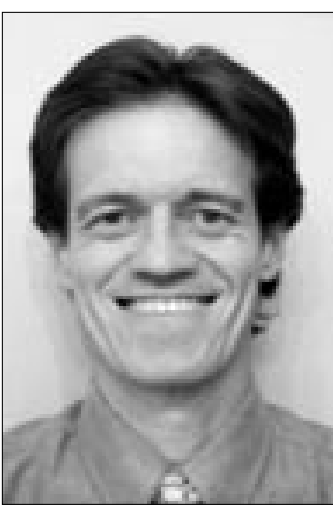

Figure 5. Dr. Paul A. Grayburn. a broad and major impact on BUMC's reputation and day-today activities. Therefore, as his research career started to wind down, BUMC and the Department of Internal Medicine decided to make a major effort to attract an individual, or individuals, with impeccable clinical research credentials to replace him. We identified gastroenterology and cardiology as two areas in which physician/scientists would have the greatest impact on the institution and the medical staff. The administration, led by Joel Allison (chief executive officer of Baylor Health Care System) and Tim Parris (president of BUMC), enthusiastically supported the efforts to recruit such individuals. We were especially eager to attract physician/scientists who would carry out category 1 research (hypothesis-driven basic and/or clinical research) that would generate publications in journals of the first rank.

After an international search, Dr. C. Richard (Rick) Boland, the chief of gastroenterology at the University of California at San Diego, was identified as the individual we wanted to eventually replace Dr. Fordtran. Dr. Boland has an outstanding reputation as a specialist in gastrointestinal malignancy and the genetics of carcinogenesis. His scientific investigation focuses on fundamental medical genetics. Dr. Boland was one of the first to recognize defective mismatch repair genes as a significant cancer risk factor as well as the clinical impact of "microsatellite instability." During BUMC's recruiting efforts, Tim Parris said he would "personally fly out to San Diego and drive Dr. Boland's U-Haul back to Dallas, if needed." More importantly, the administration supported the recruitment efforts with promises of generous laboratory space and financial support. Dr. Boland agreed to become BUMC's new chief of gastroenterology in 2003, and his laboratory was relocated to Dallas together with several key personnel (Figures 4 and 6). The lab is up and running, and major discoveries and publications are anticipated. Recent interests include the role of viruses in the causation of cancer.

Almost simultaneously, Dr. Gary L. Davis was recruited to head the liver disease subdivision. Dr. Davis' research program was discussed above in relation to the gastrointestinal division.

In 2002 Dr. Paul A. Grayburn was recruited to a full-time position as a professor of cardiology research (Figure 5). A widely respected researcher and clinician specializing in echocardiography, Dr. Grayburn's research spans the spectrum from small-animal studies to individual patients and large multicenter trials. Very importantly, Dr. Grayburn is a recognized leader in these trials, generates hypotheses, and is a major contributor to the protocols. BUMC has become the echocardiogram reference 
center for several NIH-sponsored trials. Dr. Grayburn's direct participation in the writing process, presentation of data at national and international meetings, and eventual publication result in much greater recognition for him and for BUMC. Dr. Grayburn has relocated his small-animal laboratory to BUMC and continues his studies of sonographic-directed and -activated drug and gene delivery systems. As was the case with Dr. Boland, the BUMC administration, led by Mr. Allison and Mr. Parris, played a major role in this recruitment and ensured that BUMC could offer adequate space and support to attract a well-established scientist to our campus.

The recruitment of Drs. Boland and Grayburn signifies a new era at BUMC. These men were recruited because they are outstanding researchers. Their success will be measured by the quality of their original, hypothesis-driven research, their ability to attract competitive funding, and the publication of their results in excellent peer-reviewed journals. The Fordtran lab showed that this was possible on the BUMC campus, and it is our intention and commitment to continue and expand the research legacy he has created for BUMC.

\section{SUBSPECIALTY FELLOWSHIPS}

In 1979 the Department of Internal Medicine had subspecialty fellowships in cardiology, gastroenterology, medical oncology, infectious diseases, nephrology, rheumatology, and pulmonary medicine. These were under the direction of division chiefs and almost entirely supported by the private-practice subspecialty physicians rather than by BUMC. Training was based on the preceptor concept, with little research experience. Some subspecialties had fellows only intermittently, while others had fellows continuously. Despite the lack of research training, these programs produced excellent subspecialists, many of whom stayed at BUMC. These fellowships helped BUMC recruit better residents because many students want to train at an institution that also offers subspecialty education.

Over the past 2 decades, the Accreditation Council for Graduate Medical Education, which regulates and certifies postgraduate medical training, developed progressively more stringent requirements for fellowship programs, including a substantial research component and outpatient training opportunities. Each fellowship was required to have at least two active fellows at any time, and institutions were required to have a minimum of three fellowships. Each fellowship director must devote at least 25\% of his or her time to the program, and at least four other faculty members must dedicate a minimum of $10 \%$ of their time to fellowship training. Consistent vacancies in approved fellowship positions are not allowed. As a result of these new and more stringent requirements, many fellowship programs closed, and by the late 1990s BUMC had only three fellowships (cardiology, medical oncology, and gastroenterology).

The demand for these three BUMC fellowships is currently very high, with a hundred or more applicants for each fellowship slot. Consequently, each program is able to recruit outstanding trainees. Fellowships continue to be a very important recruiting issue for our residents, and they produce outstanding subspecialists. The stipends for fellowships are increasingly paid by BUMC rather than by private groups, and this support has improved these programs. Dr. Larry Schiller is director of the gastroenterology program, Dr. Marvin Stone is director of the medical oncology program, and Dr. Peter Wells is director of the cardiology program.

\section{MEDICAL ETHICS AND HUMANISM}

A multidisciplinary medical ethics committee was organized at BUMC in 1983 and was initially cochaired by a vascular surgeon, Dr. Don Hunt. Dr. Lloyd Kitchens, an oncologist, was an early important member of that committee. A young internist, Dr. Robert Fine, developed a special interest in medical ethics and became its champion within the Baylor community, serving as the ethics committee's first chairman (3). He sought independent education and began to network with medical ethics experts at UT Southwestern, at Southern Methodist University, and throughout the nation. He became the leading educator in medical ethics at Baylor. He is responsible for teaching some of the medical ethics courses at UT Southwestern and is responsible for medical ethics education in the residency program at Baylor. He and Dr. Marvin Stone recently taught an American Medical Association-sponsored ethics course on care at the end of life. The ethics committee at Baylor is a very active one and is a major resource for families, physicians, the nursing service, and the administration.

\section{DIVISIONS OF INTERNAL MEDICINE}

Within the Department of Internal Medicine, 12 entities are recognized as divisions: general internal medicine, allergy and immunology, cardiology, dermatology, endocrinology and metabolism, gastroenterology, hematology and medical oncology, infectious diseases, nephrology, neurology, pulmonary disease, and rheumatology (Figure 6).

\section{General internal medicine}

During his tenure, Dr. Fordtran did much to ensure that general internists have a more visible role at BUMC. In the 1980s, he created a Division of General Internal Medicine, and the chief of this division was able to join other division chiefs on the medical board. Dr. Mark Armstrong was selected to be the first chief of general internal medicine. The general internists now hold quarterly meetings, chaired by the chief, that are well attended. There is a free flow of information and ideas to provide an opportunity for the general internists to air concerns about the department or the hospital.

Dr. Fordtran also recruited the general internists to discuss interesting unknown cases at grand rounds. At age $70+$, Dr. Paul Thomas was the first discussant, and for years only general internists were discussants. The clinicopathological conferences at grounds rounds were an opportunity for the housestaff to present and for the general internists to demonstrate their ability to discuss a complex unknown case.

Dr. George DeVaney was the physician for Robert Priddy, an oilman from Wichita Falls. Mr. Priddy approached Dr. DeVaney with the proposal to give money to BUMC and asked for help in channeling his donation. Dr. DeVaney discussed this with Dr. Fordtran, who was certainly interested in obtaining this donation for medical teaching at BUMC. Dr. Fordtran felt that Mr. Priddy's gift could help establish a professorship in general internal medicine at BUMC. Because Mr. Priddy did not want this to be called the "Priddy professorship," it was entitled the 

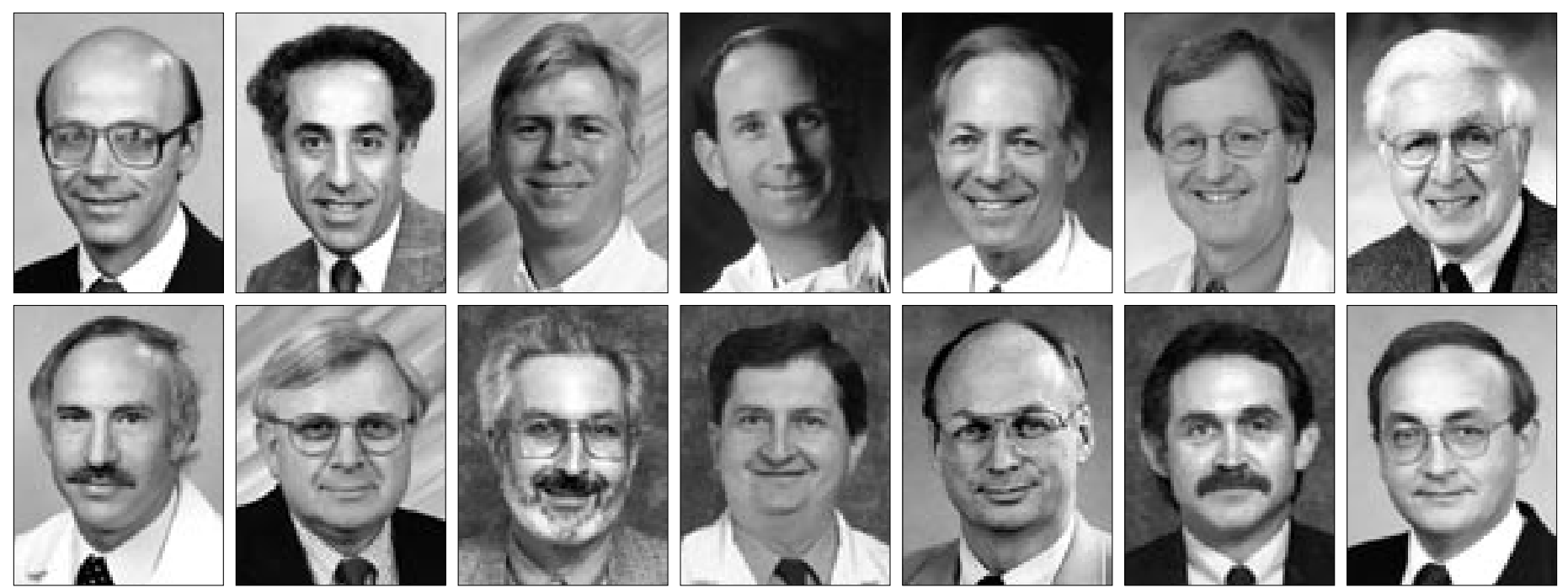

Figure 6. Current division directors in the Department of Internal Medicine. First row: Dr. W. Mark Armstrong, general internal medicine; Dr. Gary N. Gross, allergy and immunology; Drs. John R. Schumacher and Kevin R. Wheelan, cardiology; Dr. M. Alan Menter, dermatology; Dr. C. Richard Boland, gastroenterology; and Dr. Marvin J. Stone, hematology and medical oncology. Second row: Dr. Barry Cooper, hematology; Dr. Robert Mennel, oncology; Dr. William L. Sutker, infectious diseases; Dr. Andrew Z. Fenves, nephrology; Dr. Gary L. Tunell, neurology; Dr. Robert D. Black, pulmonary disease; and Dr. Andrew Chubick, rheumatology.

Baylor Professor of Internal Medicine. Dr. Fordtran asked Dr. Armstrong to fill this position.

A major change in the practice of internal medicine at BUMC came about in 1993 when Drs. David Winter, Paul Muncy, Paul Neubach, Mark Armstrong, Weldon Smith, Paul Madeley, and Michael Highbaugh merged their practices and became MedProvider. They were joined by other small internal medicine groups, and in 1995 MedProvider became part of Baylor's HealthTexas Provider Network. Over the next several years, MedProvider added new physicians to its group and now has 27 general internists practicing in the same location. Many other internists on the BUMC staff continue to practice alone or in small groups.

Hospitalists. During Dr. Fordtran's tenure, the Texas Primary Care (TPC) physician group was organized to admit unassigned medicine patients from the emergency room - a program endorsed by the medical advisory committee and the internal medicine department and supported by the administration (4). In the late 1990s, MedProvider began a second hospitalist group, which was organized for several reasons. One was to have a group that would accept the geriatric patients admitted from the Baylor Senior Health Centers. The senior health centers were established in the community by Baylor, and the physicians working at the senior centers did not have nor want admitting privileges at BUMC. The hospitalist group was also expected to admit patients from other physicians, especially those who had never admitted their patients to BUMC previously. It was hoped that it would be very easy for primary care physicians, for instance, in Mesquite or Oak Cliff, to direct their patients to a hospitalist at BUMC. The general internists who office in the BUMC area could also use this hospitalist group to admit their patients, even if the physician was not associated with MedProvider or HealthTexas. Drs. Rainer and Roger Khetan were chosen to establish this hospitalist group. They were joined by Rainer's wife, Dr. Anita Khetan, as well as Dr. Lisa Luke and Dr. Mandy Thompson, and this group was initially coordinated by Dr. Robert Baird, a pulmonologist at BUMC. Now, most admissions to the medicine service from
BUMC general internists go to the MedProvider hospitalist group or to the TPC group. Some private internists at BUMC continue to admit and care for their hospital patients, but this number has grown smaller. One of the negatives about the new system is that the housestaff are not exposed to as many private clinicians as they were in the past. The hospitalists have a subdivision within general internal medicine, as it is important for them to discuss topics, such as carepaths and protocols that are used more extensively by those physicians.

Geriatrics. Geriatrics is a subdivision of general internal medicine, and the geriatric patients admitted to the hospital are cared for by general internists. There are geriatric specialists at the Baylor senior centers, but they do not maintain admitting privileges. Dr. Wilson Weatherford is the chief of geriatrics for Baylor Health Care System. Outpatient geriatric programs include the Baylor Senior Health Centers, the Geriatric Assessment Center, and several nursing home affiliations. The senior health clinics have provided access to excellent medical care for elderly patients. The centers are located throughout the metroplex and have support services available. Patients of these centers are referred to BUMC specialists, and when they require hospitalization they come to BUMC. Many of these patients would not have had access to Baylor and Baylor physicians were it not for the senior centers. The centers have also provided employment for some senior physician internists who transitioned from their private practice to retirement. The Geriatric Assessment Center offers an in-depth evaluation and may be accessed through physician referral or self-referral. A housecall program for the homebound geriatric patient is also available through the geriatric program.

\section{Allergy, asthma, and immunology}

In the early 1980s Dr. Gary Gross, a prominent allergist in Dallas, shared a plane ride home with Dr. Fordtran from Toronto. Dr. Gross had trained in pulmonary medicine at UT Southwestern and had done a fellowship in allergy at Jewish Hospital in Denver, a nationally renowned program. They decided that an asthma center at BUMC would be advantageous for the institution 
and for patients. They envisioned an educational center where patients could come and receive comprehensive education that could not be provided in private physicians' offices. The asthma center gained the support of the administration, and Dr. Gross was named the first medical director of the center. Later, Dr. Mark Millard became the director of the asthma center, which continues to be a major educational resource for patients and physicians. The patients remain under the care of their private physicians, receiving only educational input from the physicians at the asthma center.

\section{Cardiology}

Cardiology was not always the highly technical subspecialty that it has become. Once a cardiologist spent a great deal of time evaluating patients with valvular or rheumatic conditions. Many office-based physicians whose formal training in cardiology was variable practiced cardiology. The need for a high-tech center did not arise until cardiac catheterization became a reality (5). Dr. Ralph Tompsett brought Dr. John Hyland to BUMC to be the first hospital-based cardiologist and to establish the "faculty" paradigm that developed under his tenure (3).

During Dr. Tompsett's tenure, Dr. Hyland and his partners were the only cardiologists allowed to have privileges within the catheterization lab. One of these physicians, Dr. Charles Harris, a fully trained cardiologist, decided to leave the hospital-based group but wanted to have an office in the BUMC complex and continue to have catheterization privileges. This request was denied by Drs. Tompsett and Hyland based on their concept that the hospital-based group had been given, in essence, a "franchise" of the catheterization lab, similar to the radiology group's exclusive rights to read all $\mathrm{x}$-rays at BUMC. There was considerable resentment of this decision, as Dr. Harris was a popular consultant with many of the general internists. Nonetheless, the decision held, and Dr. Harris left BUMC to establish his practice at Medical City Hospital.

The next important decision came early in Dr. Fordtran's tenure as chief of medicine when Dr. John Schumacher, a graduate of the BUMC residency program, completed his cardiology fellowship at BUMC. It was Dr. Fordtran's philosophy that if BUMC residents and fellows completed their training here and were qualified to be on the staff, they should have full privileges. Dr. Schumacher was not invited to become a part of the hospital-based group but wanted to stay at BUMC. In addition, Dr. Robert Rosenthal was completing his cardiology training at UT Southwestern and wanted to come to BUMC to practice. These two young men decided to become partners and applied for hospital and catheterization privileges at BUMC. Dr. Fordtran felt strongly that Dr. Schumacher should be allowed privileges in the catheterization lab and presented this to BUMC administration. To gain support for his decision, Dr. Fordtran depended heavily on the advice of the medical advisory committee, and the topic was discussed at many lengthy sessions. Finally, the medical advisory committee backed Dr. Fordtran in his decision. Over the objection of many, Dr. Schumacher was given privileges in the catheterization lab. This was the genesis of the second-largest cardiology group at BUMC. It was the perception of the general internists that this decision improved the cardiology services, and this was attributed to the competition generated by the second group (5). Several cardiologists were quickly added to Dr. Schumacher's and Dr. Rosenthal's group, which became Cardiology Consultants of Texas. The hospitalbased group became HeartPlace and also grew. As cardiology has evolved with subspecialization, both groups added cardiologists in important areas, including interventional cardiology, electrophysiology, and congestive heart failure and in the noninvasive cardiology arenas.

In the early 1990s, Cardiology Consultants of Texas asked to have a larger role in the administration of the heart center. Specifically, Dr. Michael Sills and the noninvasive cardiologists from that group wanted to be able to interpret more of the noninvasive studies that were done in the hospital. This led to another long discussion within the medical advisory committee on how cardiology is practiced at BUMC. Through Dr. Fordtran and backing by the medical advisory committee, changes were made. Each committee member met with at least two cardiologists, members of the noninvasive lab, and cardiothoracic surgeons. The pros and cons of changing the noninvasive lab were analyzed and debated. Quality and patient care were considered, as well as efficiency in the lab and fairness to the cardiologists. It was decided to allow more participation in the administration of the noninvasive lab and to allow cardiologists other than the hospital-based group to read echocardiograms and tests ordered by physicians other than members of their own group. General internists were allowed to choose which cardiologist or group of cardiologists would read the echocardiogram or noninvasive study. Dr. Sills replaced Dr. Charles Gottlich as the medical director of the noninvasive lab.

The timing of this controversy arose when Dr. Hyland turned 65. Dr. Fordtran had an unwritten rule that department heads and division chiefs should serve only until they were 65 years old and then step down to allow for continued evolution of the department/division. Several options for finding a replacement for Dr. Hyland were discussed, including bringing an independent cardiologist from the outside to become the chief. However, this option would be very expensive, and it was unclear how a new chief would interact with the two existing groups. After many long discussions, it was determined that Dr. Fordtran would be the acting chief of cardiology for administrative purposes only and would meet with cochiefs from each of the two large cardiology groups. Dr. Kevin Wheelan and Dr. John Schumacher were chosen for those cochief positions. Dr. Fordtran met with them and members of the heart center administration weekly to try to resolve problems within the division. This system continued and remained in place at the time of Dr. Fordtran's retirement. The cochiefs have maintained a cooperative relationship and have worked with all cardiologists to make this division nationally recognized.

Later, North Texas Cardiology Consultants developed when several cardiologists left HeartPlace, leading to three large cardiology groups and one independent cardiologist, Dr. Calixto Romero, who all share privileges in the catheterization lab and the heart center. The Division of Cardiology is considered to be an outstanding one, filled with subspecialists in all fields of cardiology. Numerous cardiologists have come to BUMC, and BUMC is recognized as the leading hospital for cardiology in North Texas.

Members of all three groups are involved in running the division. Drs. Wheelan and Schumacher are directors of the cath- 
eterization lab, Dr. Cara East is director of the noninvasive lab, Dr. Tom Andrews is director of the coronary care unit, Dr. Carlos Velasco chairs the cardiology quality assurance committee, and Dr. Ravi Vallabhan coordinates the cardiology noon conference lectures. Dr. Romero, now retired from private practice, continues to hold teaching conferences for residents and medical students. Dr. Hyland has continued to give a 2 -week electrocardiogram course every 2 years at the noon conference hour.

The cardiology fellowship program continues to be run by the HeartPlace group, and Dr. Peter Wells is the program director. This program has attracted many excellent fellows and has gained an increasingly favorable reputation.

In 2002 Dr. Paul Grayburn was named the Paul Thomas Chair of Cardiology at BUMC. Dr. Grayburn was previously chief of cardiology at the Dallas VA Hospital, where he had established himself as an excellent teacher, researcher, and clinician. He will continue his research projects at BUMC.

\section{Dermatology}

Dermatology has remained a division within the Department of Internal Medicine. Dr. Coleman Jacobson became the chief of dermatology during Dr. Tompsett's tenure as chief of medicine. During Dr. Tompsett's era, many dermatologists were practicing in small groups in the BUMC area. Dr. J. B. Howell, in particular, was a well-respected, internationally recognized dermatologist who practiced at Baylor for many years. He was prominent in educating the public about early diagnosis of melanoma. Dr. Neal Schneiderman was also a well-recognized dermatologist on staff. During this era, Dr. Roberta Simon came to BUMC from her residency in New York City and remains an active member of the dermatology division. Dr. Coleman Jacobson built an excellent group of dermatologists and recruited Dr. Alan Menter in 1975 and Dr. David Whiting in 1978. Dr. Whiting has an international reputation in the diseases of the scalp and hair and leads the hair clinic at BUMC. Dr. Jacobson's original group continues to be the largest group on campus and includes Drs. Laura Sears, Mary Fleischli, Chris Crawford, and Jerald Sklar.

Dr. Alan Menter originally was a member of Dr. Jacobson's group but left in 1983 to establish a separate practice group. Dr. Menter succeeded Dr. Jacobson as chief of dermatology and has been responsible for the dermatology teaching program for the past 15 years. Each internal medicine resident is required to spend a month rotating in dermatology offices to gain experience with this discipline. This rotation has always been popular and adds to the residents' experience.

The Psoriasis Center was started at BUMC in the late 1970s and was led by Dr. Menter. This center was involved in major research efforts in the field of psoriasis. Dr. Menter gained a national reputation as a leader in the clinical aspects of psoriasis. This center continues but is no longer an official part of Baylor.

\section{Endocrinology and metabolism}

Dr. Zaven Chakmakjian was an internal medicine resident at BUMC who returned to be a hospital-based endocrinologist after his fellowship at the University of Southern California. At that time, endocrinology was practiced by independent groups, but there was no strong presence at BUMC. In 1976, after completing his training at the NIH, Dr. Samuel Marynick joined Dr.
Chakmakjian. These physicians practiced together for several years but later separated to form independent practices. Dr. Mark Leshin came to BUMC from UT Southwestern and established his private office. Dr. Chakmakjian recruited Drs. Neil Breslau and Raphaelle Vallera.

Dr. Marynick, in conjunction with Dr. Mike Putman, established the Baylor Center for Reproductive Health. He and the center have become well recognized for their efforts in treating infertility. The internal medicine residents now rotate with the endocrinologists at BUMC, primarily spending time in Dr. Chakmakjian's office.

The Ruth Collins Diabetes Center was also developed at BUMC under Dr. Tompsett's administration. Originally, Dr. Zaven Chakmakjian was the director of this center. The emphasis of this center, like that of the asthma center, is on patient education, as it is not intended for patients to receive their diabetic care from physicians at the diabetes center. Dr. Michael Emmett became the medical director of the diabetes center in 1986 and continued in that role until Dr. Priscilla Hollander, a nationally recognized diabetes educator, was recruited to fill the position in 1998. The diabetes center continues to be an excellent source for patient education and is widely used by the primary care physicians in the BUMC community. Dr. Hollander has been involved in important clinical research since becoming the medical director.

\section{Gastroenterology}

Gastroenterology has always had a strong presence at Baylor. Early on, Drs. Cecil Patterson and Milford Rouse were nationally recognized gastroenterologists and developed a strong private group in the Baylor area. There were several gastroenterologists at Baylor who performed procedures in their private offices. Gastroenterology underwent a profound change with the advent of the fiber-optic endoscope in the 1950s and 1960s. It grew from being a cognitive and diagnostic discipline to the first specialty that performed minimally invasive surgery. From endoscopic resection of colon polyps to the treatment of unresectable pancreatic cancer, gastroenterology became the preferred specialty for treatment of many diseases that formerly required surgery.

When Dr. Tompsett was establishing a faculty and hospitalbased approach at BUMC, he persuaded Dr. Dan Polter to leave his position as chief of gastroenterology at the Dallas VA Hospital, an affiliate of UT Southwestern, to become the chief of gastroenterology. A long-time resident of Dallas, Dr. Polter had gone to medical school at UT Southwestern and done his medicine residency there. After that, he completed a gastroenterology fellowship at the University of California at Los Angeles before returning to Dallas. In 1971, the gastroenterology lab opened in the Veal Building. The lab was capable of performing most of the "cutting-edge" procedures that were employed at that time. The original laboratory comprised two procedure rooms and one fluoroscopy room. During construction a fireplace was uncovered at the end of the hall, attesting to the age of the building. Patricia Crumlish, RN, was the first gastroenterology lab supervisor. She held the position for 16 years and was instrumental in developing many policies to ensure patient safety, including endoscopic disinfectant procedures that were not popular with gastroenterologists. The gastroenterology lab currently has 8 procedure rooms and 18 recovery beds. Lab volume has continued to grow in spite of the 
development of multiple ambulatory endoscopy centers competing for patients. Major recent advances in gastroenterology lab technology include video endoscopy and a computerized reporting system. In the past, about $75 \%$ of gastrointestinal procedures were done in an inpatient setting. This has changed, and now $80 \%$ of gastrointestinal procedures are done on an outpatient basis. In October 2003, 1354 procedures were done in the BUMC gastroenterology lab, a record. Screening colonoscopies have become an important factor in this trend.

In 1974 Dr. Charles Walker joined Dr. Polter as a second hospital-based gastroenterologist. He was an expert in nutrition and was instrumental in developing parenteral nutrition services at BUMC. In 1975 Dr. Kent Hamilton came to BUMC to complete his gastroenterology fellowship after spending his first year at the Cleveland Clinic. He later joined the hospital-based group. He performed the first endoscopic retrograde cholangiopancreatogram at BUMC and became a leader in developing new therapeutic procedures, including endoscopic retrograde cholangiopancreatography, percutaneous endoscopic gastrostomy, balloon dilatation of upper gastrointestinal strictures, and endoscopic stent placement in the upper gastrointestinal tract, colon, bile ducts, and pancreatic duct. Dr. Daniel DeMarco completed his gastroenterology fellowship at BUMC in 1984 and joined the hospital-based group at that time. He has been instrumental in developing new technology at BUMC, including endoscopic ultrasound, endoscopic techniques for treating gastroesophageal reflux, and capsule enteroscopy. He recently was made director of the gastrointestinal laboratory.

The hospital-based clinical gastroenterologists, in association with Drs. Katherine Little, Lawrence Schiller, and Kenneth Fine, continued to be involved in the gastroenterology fellowship program at BUMC. Dr. Polter was the director of the program for many years, but that position is now held by Dr. Larry Schiller. Dr. Schiller has organized the fellowship program and has been instrumental in furthering its reputation. Having Dr. Fordtran as the chief of medicine for many years increased the reputation of gastroenterology and its fellowship program.

Dr. Charles Walker left the hospital-based group and with Dr. Charles Richardson, who came from UT Southwestern, established the second-largest gastroenterology group at BUMC. This group is now five members strong and is headed by Dr. Richardson. They have become an important part of the teaching program, along with the hospital-based group.

Other gastroenterologists, including Drs. Michael Allen, William Santangelo, and Christopher Vesy, contribute to the strength of the overall practice of gastroenterology at BUMC.

The gastroenterology division has been responsible for caring for patients with liver disease as well. When the liver transplant program at BUMC was established in 1984, the hospital-based gastroenterology group was crucial to the success of the program. Dr. Polter was able to recruit Dr. Jeffrey Crippin in 1992 to be the chief of hepatology and the medical director of the liver transplant program. He brought another Mayo trainee, Dr. Jeffrey Weinstein, to be his associate. Dr. Crippin developed a national reputation and stayed at BUMC until 2000. Upon the departure of Dr. Crippin, Dr. Weinstein became the acting interim chief of hepatology and he was joined by Dr. Natalie Murray. Dr. Gary Davis came as chief of hepatology in 2002.
In 2003, Dr. C. Richard Boland succeeded Dr. Polter as director of the Division of Gastroenterology. Dr. Boland has served on the faculties of the University of California at San Francisco, the University of Michigan School of Medicine, and, most recently, the University of California at San Diego, where he was a professor of medicine, chief of the division of gastroenterology, and associate director of clinical research in the comprehensive cancer center. He has published more than 340 scientific articles, chapters, and abstracts. Dr. Boland will focus on basic and clinical research related to the biology, diagnosis, and treatment of colorectal cancer.

When Dr. Fordtran was named the chief of medicine at BUMC, he envisioned a digestive disease center at BUMC. Dr. Katherine Little was invited to become the medical director of the newly established Diagnostic Center for Digestive Diseases at BUMC. This center provided office space for gastroenterologists to see their patients. It provided a site where private physicians could send interesting or difficult cases to be evaluated by the expert gastroenterologists at BUMC. The center is located on the third floor of Truett Hospital, which was physically adjacent to the gastroenterology lab. Dr. Little has continued to be the director of this center of excellence. Upon Dr. Fordtran's retirement as chief of medicine, the center was renamed the John S. Fordtran Diagnostic Center for Digestive Diseases in his honor.

\section{Hematology and medical oncology}

When Dr. Tompsett was building his internal medicine faculty, he made a very important decision in choosing Dr. Merrick (Mike) Reese to become the head of hematology and oncology. Dr. Reese's role extended beyond this division, as he was the director of medical education at BUMC. He is credited with actively recruiting many of the internal medicine residents who came to BUMC during the 1970s. Dr. Reese was energetic, charismatic, innovative, and forward thinking. The quality of the internal medicine program rose dramatically during Dr. Reese's tenure as the director of medical education (3).

When Dr. Reese came to BUMC, oncology was not the welldeveloped subspecialty in internal medicine it has come to be. At that time the disciplines of hematology and oncology were combined into a single subspecialty. Dr. Reese, nonetheless, could envision the growing need for practicing oncologists and began to build an excellent group at BUMC. His first addition was Dr. J. R. Williams, who, following a fellowship in Boston, established his hematology/oncology practice in Midland/Odessa and then relocated to BUMC. They were shortly thereafter joined by Dr. John C. Bagwell, who had begun to practice within his father's internal medicine group at BUMC. They quickly added one of their own residents, Dr. Lloyd Kitchens, and a graduate of the UT Southwestern program, Dr. Lewis Duncan. At about the time the Baylor cancer center was being established, Dr. Reese was instrumental in convincing Dr. Marvin Stone to leave his position at UT Southwestern to come to BUMC as the head of the Sammons Cancer Center. This was a coup for BUMC and the new center, as Dr. Stone had already established an excellent reputation in both hematology and oncology. Dr. Reese and these physicians formed Texas Oncology, a group of physicians that grew to include not only the hematology/oncology group at BUMC but also oncologists throughout all parts of Dallas and, 
indeed, throughout Texas. They were able to attract well-trained and well-respected physicians from all over the nation. Dr. Stone became the chief of hematology/oncology when he arrived to head the cancer center. Dr. Barry Cooper and Dr. Robert Mennel arrived in 1979 and were appointed codirectors with Dr. Stone of hematology and medical oncology, respectively.

Dr. Cooper received his hematology training at the Peter Bent Brigham Hospital in Boston and was asked to stay on the Harvard faculty as chief of hematology at the West Roxbury VA Medical Center. His primary interests have been in hematologic malignancies and coagulation. Dr. Mennel came to BUMC following fellowship training at Johns Hopkins. He became professor of oncology and internal medicine in 2000. Drs. Cooper, Mennel, and Stone have been active in teaching residents, medical students, and fellows, and each has been recognized with teaching awards from the internal medicine housestaff. Dr. Steven Paulson, a leader and longtime member of the BUMC staff, became president of the oncology practice group (Texas Oncology, PA) in 2000.

The oncology group has maintained a fellowship program at BUMC that has been extremely popular, especially with the BUMC housestaff. It is not unusual for one or two members of the housestaff to seek a fellowship in oncology at BUMC. Dr. Marvin Stone has been the director of the fellowship program, and the fellows gain their clinical experience in the offices of the oncologists at Sammons Cancer Center.

When bone marrow transplantation emerged as a technology for treating patients with hematologic and solid organ malignancies, Dr. Joseph Fay was recruited from Duke to become the director of the bone marrow transplant unit. He, along with Dr. Robert Collins, a former BUMC resident who had trained at the University of California at Los Angeles, rapidly developed one of the busiest bone marrow transplant units in the nation. When Dr. Fay left to concentrate his efforts at the Baylor Research Institute, Dr. Edward Agura became the medical director of the bone marrow transplant unit.

Physicians of Texas Oncology, PA, have participated in many clinical trials, oftentimes as part of the Southwest Oncology Group, a coalition of oncologists who do important clinical studies. They have been especially important in studies involving lymphoma and breast cancer.

\section{Infectious diseases}

Dr. Tompsett established the Division of Infectious Diseases, as that was his specialty. One of his residents, Dr. William Sutker, completed a fellowship under Dr. Tompsett and joined him in the private practice of infectious diseases at BUMC. Dr. Sutker became the chief of infectious diseases upon the retirement of Dr. Tompsett. He has been instrumental in the educational program at BUMC, serving as the director of medical education, and he has continued to maintain a busy infectious disease practice. He was joined by two of his fellows, Drs. Louis Sloan and Cristie Columbus, and in 2003 by a former BUMC resident, Dr. Marc Tribble. In addition to his practice at BUMC, he maintains an infusion center for the outpatient administration of antibiotics. Dr. Cynthia Schneidler has an independent practice of infectious diseases at BUMC.

When HIV appeared in the 1980s, general internists were ill prepared to deal with the complexity of caring for patients with this complicated disease. The infectious disease physicians were obviously heavily involved. Dr. Brady Allen, a general internist at BUMC, took a special interest in HIV disease. He became an expert in the diagnosis, management, and support of patients with AIDS. Over the years, he and the infectious disease division have been the major resources for the education of the housestaff in care of patients with AIDS.

\section{Nephrology}

When dialysis became a mainstay of therapy for chronic renal disease, Dr. Charles Austin was the nephrologist most involved in the care of the dialysis patients at BUMC. Although Dr. Austin was not hospital based, he was primarily responsible for the nephrology teaching program at BUMC. In 1975, Dr. Martin White was recruited from his position as chief of nephrology at the Dallas VA Hospital to become chief of nephrology at BUMC. Dr. White and his citywide group attracted Dr. Michael Emmett from his fellowship at the University of Pennsylvania to come to BUMC in 1976. The two of them, with their associates, were responsible for all of the nephrology efforts at BUMC for many years. As more nephrologists were needed at BUMC, their group expanded to include Drs. Mark Lerman and Andrew Fenves. Dr. White became more involved in the administration of the citywide group (Dallas Nephrology Associates) and stepped down as the chief of nephrology; in 1986, Dr. Emmett assumed this position.

When solid organ transplantation became a significant procedure at BUMC, Drs. Thomas Gonwa and Martin Mai were the nephrologists primarily responsible for renal transplant medicine. In 1996, when Dr. Emmett assumed his new role of chief of internal medicine at BUMC, Dr. Robert Kunau, a colleague who had had an academic career at the University of Texas at San Antonio, became the chief of nephrology. Dr. Kunau left BUMC to return to San Antonio in 1999. Dr. Andrew Fenves was then named the chief of the Division of Nephrology, and Dr. Steven Hays became the director of the dialysis unit. Dallas Nephrology Associates sponsors an annual lectureship named in honor of Dr. Austin. Nationally prominent nephrologists are invited to BUMC to give a grand rounds lecture and meet with the housestaff at a noon conference.

\section{Neurology}

Initially, neurology was practiced at BUMC by independent physicians practicing on or near the BUMC campus. As part of Dr. Tompsett's efforts to create a faculty system at BUMC, Dr. Sheff Olinger, one of the first board-certified neurologists in Texas, was recruited from his private practice to become the first chief of neurology at BUMC in 1965. Dr. Olinger was prominent in neurological circles in Texas and the Southwest. In 1979, he was cross-examined by Melvin Belli about the results of Jack Ruby's electroencephalogram. In 1979, Dr. Herbert Leiman completed his residency in neurology at Mount Sinai in New York and established his private practice of neurology at BUMC. He has continued to practice independently and has been a vital participant in the neurology teaching program at BUMC. In 1981, Dr. Gary Tunell completed his neurology residency at UT Southwestern and established a private practice near the BUMC campus. He then actively recruited other residents from the UT Southwestern program, including Drs. Steve Herzog, Alan Mar- 
tin, Bruce Jenevein, Darough Heitzman, Ted Phillips, and Waleed El-Feky. Drs. Fish Greenfield and Lise Labiche more recently joined the group that practices as Texas Neurology. Dr. Jorge Romero came to BUMC in 1998 following an academic career in Boston and maintains a private practice.

All internal medicine residents rotate on the neurology service, usually in the offices of Texas Neurology. They see both outpatient and inpatient consultations, working with staff neurologists. The neurology service is responsible for interpreting electroencephalogram studies, nerve conduction studies, and intraoperative procedures. Upon the retirement of Dr. Olinger in 1990, Dr. Tunell was appointed chief of the Division of Neurology. This division continues to be an integral, vital part of the Department of Internal Medicine.



Figure 7. Internal medicine residents and faculty, 2003.

\section{Pulmonary disease}

Dr. Charles Jarrett was the first chief of pulmonary medicine at Baylor. He came to Baylor after his residency and fellowship at Parkland. Before the faculty-based concept, there were several pulmonary physicians in the Baylor area, including Drs. J. O. Armstrong and George Schools. When Dr. Jarrett was drafted into military service, Dr. Charles Shuey came to Baylor from his residency program at Parkland and partnered with Dr. Jarrett on his return from the military service. These two were responsible for the teaching program in pulmonary medicine, developed the pulmonary fellowship program, developed the respiratory therapy department, developed a state-of-the-art pulmonary laboratory, and introduced fiber-optic bronchoscopy to BUMC. Their first fellow, Dr. Martin Hurst, joined the practice in the late 1970s.

In the early 1980s, Dr. Robert Baird completed his fellowship program at BUMC and established his private practice at BUMC when he was not allowed to join the hospital-based group. Dr. Hurst subsequently left the hospital-based group and became a private pulmonologist with Dr. Baird. Drs. Ken Ausloos and Michael Jordan later joined them.

Dr. David Luterman completed his fellowship at BUMC before Dr. Baird and had set up a private practice, taking call with Drs. Schools and Armstrong. Later, Dr. Mark Millard, after completing a fellowship at Yale, joined a general internal medicine group at BUMC but subsequently left to concentrate on pulmonary medicine. Both of these physicians continue to practice at BUMC. Dr. Millard is currently the medical director of the asthma center. Drs. Jarrett and Shuey continued to be the hospital-based group through the mid 1980s.

Dr. Jarrett became an influential part of the Baylor administration, becoming the first utilization review officer at Baylor. He supervised the medical staff introduction to the diagnosis-related groups when they became the form of payment for Medicare patients. As this administrative job took more time from his pulmonary practice and as his health deteriorated, he stepped down as chief of pulmonary medicine, and Dr. Shuey took over that role. He was joined in the hospital-based practice by Dr. Robert Black.

In 2000, Dr. Shuey resigned as chief of pulmonary medicine, and Dr. Black ascended to that position. During the last few years of the century, there was an effort to consolidate the pulmonologists at BUMC, and Drs. Shuey, Black, Millard, Jordan, Ausloos, and Luterman formed a group that now practices together. Dr. Hurst retired, and Dr. Baird became independent of the other pulmonologists. Dr. Shuey retired from active pulmonary practice and is now medical director of BUMC's new hyperbaric center.

\section{Rheumatology}

The Baylor Arthritis Center was founded by Drs. Richard Merriman and Andrew Chubick. Dr. Chubick was named the chief of rheumatology at BUMC, and Dr. Merriman participated in housestaff education. Dr. Eric Hurd joined them, coming from the rheumatology department at UT Southwestern. After 5 years, the hospital-based rheumatologists left the Baylor Arthritis Center to establish a private practice independent of BUMC. They founded Arthritis Center of Texas and expanded their group rapidly. The Baylor Arthritis Center ceased to exist with their departure. Dr. Chubick has continued to be the chief of the division, and the housestaff continues to rotate in the rheumatology private offices for their clinical experience. Dr. Merriman continues to work closely with the residents in the office.

\section{FUTURE CHALLENGES}

The Department of Internal Medicine faces several challenges in the coming decades. One challenge is maintaining the academic atmosphere at BUMC. As private practitioners must devote more time to office management, to increase their efficiency and deal with extra layers of bureaucracy, they have less time for the volunteer activities required to keep the educational program at its peak. A core group of physicians is still involved 
in the teaching program, but Dr. Emmett predicts that outside pressures will make it more difficult for them to participate over the next few years. The financing of medical education will be a crucial issue during the coming years. The Baylor administration has continued to support medical education, but private funding will be necessary to sustain medical education at its current base. There is strong competition for such private funding in the community. The medical school's educational program receives state funding, which BUMC's educational program does not receive. Whether BUMC can raise money through private funding to support medical education remains to be seen. The administration remains committed to education as a major priority (Figure 7).

Another challenge is recruiting clinicians to BUMC. Medical school faculty are better paid than in the past, and attracting such physicians to BUMC has become increasingly difficult. This challenge becomes particularly important since several division chiefs will be retiring and will need to be replaced. Some divisions may find a chief within their ranks, while in others it may be best to recruit a physician with national prominence.

Another continuing challenge is maintaining a cohesive Department of Internal Medicine. A concern voiced by Dr. Fordtran and echoed by Dr. Emmett is that market forces sometimes have led to a focus on "product lines" that conflicts with the traditional organization of the department of medicine. For example, the cardiovascular service line and the construction of the Baylor Jack and Jane Hamilton Hospital have in effect removed a significant portion of the cardiology service from the direct control and supervision of the Department of Internal Medicine. Fostering a sense of departmental unity seems important if we are to prevent various divisions from becoming separated from the Department of Internal Medicine.

Other major future challenges include compliance with numerous rules and regulations promulgated by the Accreditation
Council for Graduate Medical Education. The rules require innovative solutions for problems related to maximal work hours and days off. Many new curriculum requirements must also be met.

\section{Acknowledgments}

Mrs. Henry Winans, Jr., Mr. David Hitt, and Drs. John Binion, Jack Edwards, Jabez Galt, Arvel Haley, E. R. Hayes, Carey King, LeRoy Kleinsasser, Donald W. Seldin, and Elgin Ware were interviewed about the events at Baylor prior to 1957. In preparing the history of the eras of Drs. Fordtran and Emmett, Dr. Armstrong relied on interviews with them and with other medical staff members, as well as on detailed minutes of the medical advisory committee meetings. These minutes were also used by Drs. Armstrong and Emmett in preparing reports about the various divisions of the internal medicine department. In most instances, comments about the divisions were reviewed by several members of the various divisions. Drs. Dan DeMarco, Jack Hyland, Russell Martin, Paul Neubach, Dan Polter, Marvin Stone, William Sutker, Gary Tunell, and David Winter read the entire manuscript for accuracy and balance. A special thanks to Ann Drew for her assistance in preparation of this manuscript.

1. Burnett CH, Commons RR, Albright F, Howard JE. Hypercalcemia without hypercalcuria or hypophosphatemia, calcinosis and renal insufficiency: a syndrome following prolonged intake of milk and alkali. N Engl J Med 1949;240: 787-794.

2. The Burnett or milk alkali syndrome [editorial]. JAMA 1955;157:1220.

3. Fordtran JS, Armstrong WM, Emmett M, Kitchens LW Jr, Merrick BA. The history of internal medicine at Baylor University Medical Center, part 1. BUMC Proceedings 2004;17:9-22.

4. Fine RL. The history of institutional ethics at Baylor University Medical Center. BUMC Proceedings 2004;17:73-82.

5. Hyland JW. History of cardiology at Baylor University Medical Center. BUMC Proceedings 2003;16:405-421. 